\title{
Adaptive Control of a Nonlinear Aeroelastic System
}

\author{
Daochun Li, Jinwu Xiang \\ School of Aeronautic Science and Engineering, Beihang University, Beijing, 100191, P R China \\ Shijun Guo* \\ Department of Aerospace Engineering, Cranfield University, Cranfield, Bedfordshire, MK430AL, UK
}

\begin{abstract}
Aeroelastic two-dimensional wing section with both trailing-edge (TE) and leading-edge (LE) was investigated in this paper through numerical simulation in time domain. Structural stiffness and damping in pitch degree of freedom were represented by nonlinear polynomials. Open-loop limit cycle oscillation (LCO) characters of two examples were studied, and flutter boundaries with initial conditions were obtained. Parametric uncertainties in both pitch stiffness and damping were considered in the design of adaptive control laws to depress LCOs. Firstly an adaptive controller based on partial feedback linearization was derived for the wing section with a single TE control surface. Secondly a structured model reference adaptive control law was designed for the aeroelastic system with both TE and LE control surfaces. The results show that the designed control laws are effective for flutter suppression, and that considering damping uncertainty has positive effect on flutter control. It may reduce convergent time or increase flutter speed.
\end{abstract}

Keywords: Aeroelastic airfoil; Nonlinearity; Parametric uncertainty; Adaptive control.

\section{Nomenclature}

$a=$ non-dimensional distance from airfoil mid-chord to elastic axis

$b \quad=\quad$ airfoil semi-chord

$c_{l}=$ lift coefficient

$c_{l \alpha}=\partial c_{l} / \partial \alpha\left(c_{l \beta}, c_{l \gamma}, c_{m \alpha}, c_{m \beta}\right.$, and $c_{m \gamma}$ have the similar definitions $)$

$c_{h} \quad=\quad$ plunge damping

$c_{i}=$ coefficients of nonlinear damping

$c_{\alpha}=$ pitch damping

$h=$ plunge displacement

$I_{\alpha}=$ mass moment of inertia about elastic axis

$k_{h}=$ plunge stiffness

$k_{i}=$ coefficients of nonlinear stiffness

$k_{\alpha}=$ pitch stiffness

$L=$ aerodynamic lift

$M_{\alpha}=$ aerodynamic moment of wing-aileron

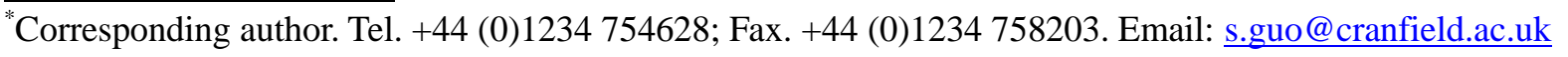




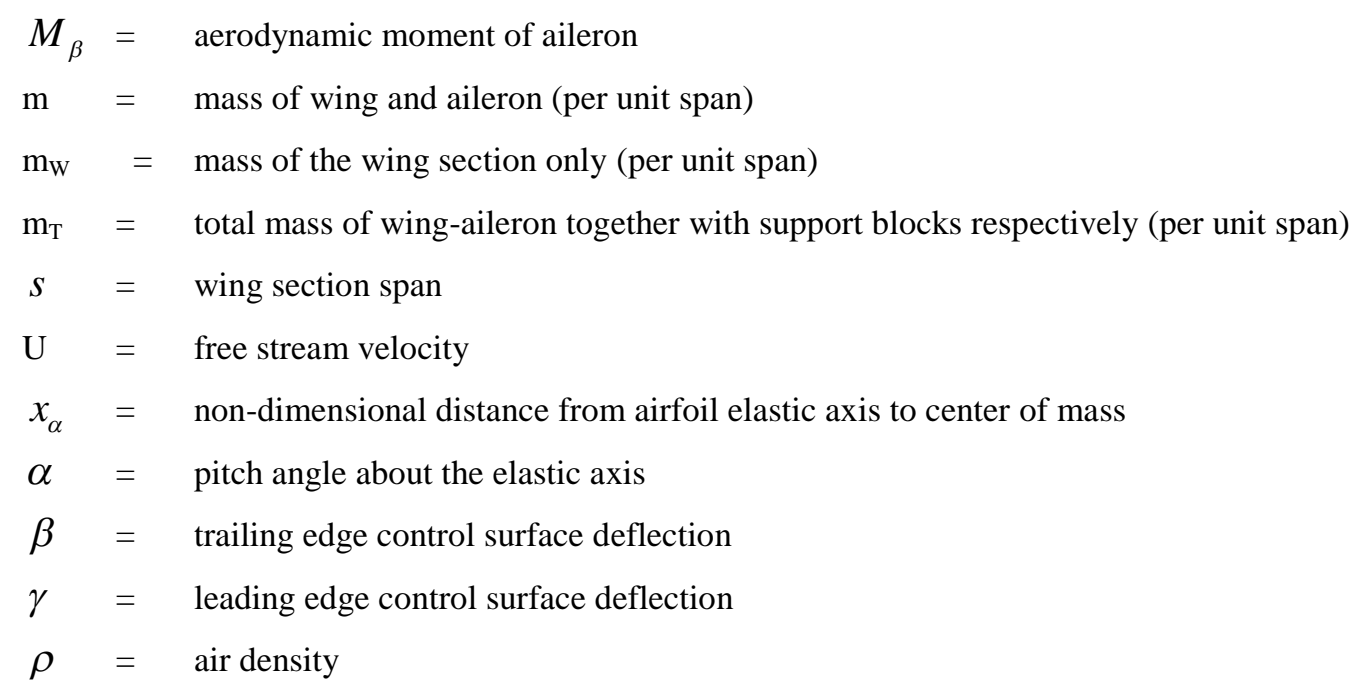

\section{Introduction}

Aeroelasticity is the field of study that deals with the interaction of structural, inertia, and aerodynamic force. Classical theories assume linear aerodynamics and structures, and the aeroelastic problem reduces to the solution of a set of linear equations that can be easily solved. However, when the airspeed increases to high subsonic or transonic Mach numbers, linear aerodynamics usually give insufficiently accurate results, an example of which is the transonic dip that linear aerodynamics fail to detect. Also, flow separation and shock oscillations can introduce phenomena, which classical aeroelasticity is unable to handle. Nonlinear aerodynamic effects are more difficult to analyze since the fluid motion is governed by equations where analytical solutions are practically non-existent $[1,2]$. A full non-linear aerodynamic code solving the Euler equations has been successfully coupled to a structural model for a two-dimensional flow case by Djayapertapa and Allen et al [3-6]. A control law was implemented within this aeroelastic solver to investigate active means of flutter suppression via control surface motion. Comparisons of open- and closed-loop calculations show that the control law could successfully suppress the flutter and results in a significant increase in the allowable speed index in transonic regime. But full CFD-CSD coupled codes are currently too time consuming to be used in the design loop, and particularly so if control law design is to be considered. Further, the lack of visibility of the full-non-linear equations in state space form makes various procedures, such as various forms of control law design, and stability analysis, extremely difficult, if not impossible. This has resulted in the creation of a reduced order model (ROM) of the Euler code [7]. The ROM has the accuracy similar to CFD method, but a time scale of operation much more comparable with that of traditional linear methods. And a comparison of full non-linear and reduced order aerodynamic models in control law design was made in Ref. [7].

On the other hand, structural nonlinearities arise from worn hinges of control surfaces, loose control linkages, material behavior and various other sources. Aging aircraft and combat aircraft that carry heavy external stores are more likely to be influenced by effects associated with nonlinear structures. With structural nonlinearities, aeroelastic system may exhibit a variety of phenomena such as limit cycle oscillation and chaotic vibration [8]. An extensive review of the analysis of structural nonlinearities for airfoil section may be found in Ref. [1].

In the past few years at Duke University, Dowell and colleagues have constructed a typical airfoil section aeroelastic experimental model with control surface freeplay. They have also designed and installed an experimental rotating slotted cylinder (RSC) gust generator in the Duke University low-speed wind tunnel, which was used to create a periodic or a linear frequency sweep gust excitation field [9]. Using these experimental facilities, a series of theoretical and experimental studies, such as flutter and LCOs [10], gust 
responses and alleviation [11], and flutter/LCO control [12, 13] have been completed. An experimental high-aspect ratio wing aeroelastic model with a device to provide a controllable slender body tip mass distribution for flutter suppression has been constructed by Tang and Dowell [14]. This study also shows the effects of the geometric structural nonlinearity as modeled by nonlinear beam theory and nonlinear aerodynamic stall theory on both the flutter instability boundary and the nonlinear limit cycle oscillation response.

For the two-dimensional wing section with structural stiffness nonlinearity, research effort has being made to develop control strategies to suppress flutter. In Ref. [15] for example, a classical linear full-state feedback control law was derived for a wing section with nonlinear stiffness to stabilize the nonlinear system in some circumstances. In Ref. [16], a partial feedback linearization methodology was applied to the design of nonlinear controllers for a nonlinear aeroelastic system. In order to derive a globally stabilizing controller, a full feedback linearization controller based on two control surfaces was designed. The stability of the closed-loop aeroelastic system was further investigated in Ref. [17]. The state-dependent Riccati equation method was developed for nonlinear control problems, and used to design suboptimal control laws of nonlinear aeroelastic systems considering both quasi-steady [18, 19] and unsteady aerodynamics [20, 21]. A global robust control law for an aeroelastic model of uncertainty was derived considering output feedback in Ref. [22].

The impact of uncertainty on aeroelastic response prediction has received substantial attention in the research literature. General sources of uncertainty that complicate airframe design and testing were briefly described by Pettit [23]. Pettit and Beran [24] investigated the effects of uncertainty on airfoil LCO by using of Monte Carlo simulation (MCS). Parametric uncertainty was modeled in the third- and fifth-order stiffness coefficients of the pitch spring. Different computational methodologies, such as Wiener-Haar, Cyclic and B-spline projection methods have been developed to quantify the uncertain response of an airfoil aeroelastic system in limit-cycle oscillation, subject to parametric variability [25]. Uncertainties are specified in the cubic coefficient of the torsional spring and in the initial pitch angle of the airfoil. When the uncertainty was considered in the flutter suppression, adaptive controllers based on partial or full feedback linearization were derived [26]. In Ref. [27], experimental results were presented to exam the adaptive controller derived by Ref. [26]. A series of adaptive controllers were derived for flutter suppression by Singh et al [28, 29], and unstructured uncertainties were also taken into account [30]. In order to improve the performance of the adaptive controller, both leading-edge (LE) and trailing-edge (TE) control surfaces were used in the design of multiple-input multiple-output control strategies in Ref. [31-33]. Recently, an output feedback control law has been implemented for suppressing flutter and reducing the vibrational level in sub-critical flight speed range [34]. An adaptive decoupled fuzzy sliding-mode controller has been presented in Ref. [35]. Based on the tensor-product model transformation and the parallel distributed compensation, a control law for prototypical aeroelastic wing section was designed and presented in Ref. [36].

In the previous references, only parametric uncertainty in pitch stiffness has been considered. In fact, the damping uncertainty in airframe structure and control system is inevitable and may have significant effect on the aeroelastic behavior [37]. However, it is very difficult to establish an accurate damping model, and the much of experimental data is normally needed. Therefore this current investigation has been focused on deriving an adaptive controller for flutter suppression of a nonlinear aeroelastic system damping uncertainty. Two examples of adaptive controller have been taken, and the numerical simulation results have been compared with that without damping uncertainty.

\section{Nonlinear Aeroelastic Model}

A generic two-dimensional wing section with leading-edge (LE) and trailing-edge (TE) control surfaces as illustrated in Fig. 1 has been considered in classical aeroelastic analysis. The elastic axis (e.a) of the model is 
located at a distance $a b$ from the mid-chord, while the mass center (m.c) is located at a distance $x_{\alpha} b$ from the e.a. The parameters $a$ and $\mathrm{x}_{\alpha}$ are positive in Fig. 1 where e.a is after the mid-chord and m.c is after e.a. measured from LE. The plunge deflection $\mathrm{h}$ is positive downward, and the pitch angle $\alpha$ about the e.a is positive nose-up. The TE and LE control surface rotation angles $\beta$ and $\gamma$ are positive downward.

The governing equation of motion of the aeroelastic model are given by [27]

$$
\left[\begin{array}{cc}
m_{T} & m_{W} x_{\alpha} b \\
m_{W} x_{\alpha} b & I_{\alpha}
\end{array}\right]\left[\begin{array}{l}
\ddot{h} \\
\ddot{\alpha}
\end{array}\right]+\left[\begin{array}{cc}
c_{h} & 0 \\
0 & c_{\alpha}(\dot{\alpha})
\end{array}\right]\left[\begin{array}{c}
\dot{h} \\
\dot{\alpha}
\end{array}\right]+\left[\begin{array}{cc}
k_{h} & 0 \\
0 & k_{\alpha}(\alpha)
\end{array}\right]\left[\begin{array}{c}
h \\
\alpha
\end{array}\right]=\left[\begin{array}{c}
-L \\
M
\end{array}\right]
$$

where $k_{\alpha}(\alpha)$ and $c_{\alpha}(\dot{\alpha})$ represent the nonlinear pitch stiffness and damping of the system, and are expressed in polynomial form as follows

$$
\begin{aligned}
& c_{\alpha}(\dot{\alpha})=\sum_{i=1}^{m} c_{i} \dot{\alpha}^{i-1} \\
& k_{\alpha}(\alpha)=\sum_{i=1}^{n} k_{i} \alpha^{i-1}
\end{aligned}
$$

In the latter adaptive controller design, parametric uncertainties are considered in both pitch damping and stiffness. $\quad c_{i}$ and $k_{i}$ are assumed to be unknown. In Eq. (1), $L$ and $M$ represent the unsteady aerodynamic lift and moment expressed by

$$
\begin{aligned}
& L=\rho U^{2} b s c_{l \alpha}\left(\alpha+\frac{\dot{h}}{U}+\left(\frac{1}{2}-a\right) b \frac{\dot{\alpha}}{U}\right)+\rho U^{2} b s c_{l \beta} \beta+\rho U^{2} b s c_{l \gamma} \gamma \\
& M=\rho U^{2} b^{2} s \bar{c}_{m \alpha}\left(\alpha+\frac{\dot{h}}{U}+\left(\frac{1}{2}-a\right) b \frac{\dot{\alpha}}{U}\right)+\rho U^{2} b^{2} s \bar{c}_{m \beta} \beta+\rho U^{2} b^{2} s \bar{c}_{m \gamma} \gamma
\end{aligned}
$$

where $c_{l \alpha}, c_{l \alpha}$, and $c_{l \beta}$ are the derivatives of aerodynamic lift coefficient caused by angle of attack, TE and LE control surface deflections respectively; $\bar{c}_{m \alpha}, \bar{c}_{m \beta}$ and $\bar{c}_{m \gamma}$ are the effective dynamic and control moment derivatives defined as

$$
\begin{aligned}
& \bar{c}_{m \alpha}=(1 / 2+a) c_{l \alpha}+2 c_{m \alpha} \\
& \bar{c}_{m \beta}=(1 / 2+a) c_{l \beta}+2 c_{m \beta} \\
& \bar{c}_{m \gamma}=(1 / 2+a) c_{l \gamma}+2 c_{m \gamma}
\end{aligned}
$$

where $c_{m \alpha}, c_{m \beta}$ and $c_{m \gamma}$ are corresponding derivatives of moment coefficient.

By defining the state variables as

$$
\mathbf{X}=\left[\begin{array}{llll}
x_{1} & x_{2} & x_{3} & x_{4}
\end{array}\right]^{T}=\left[\begin{array}{llll}
h & \alpha & \dot{h} & \dot{\alpha}
\end{array}\right]^{T}
$$

and when $\gamma=0$, Eq. (1) and Eq. (3) can be transformed into a state-space form

$$
\dot{\mathbf{x}}=\mathbf{A}(\mathbf{X}) \mathbf{X}+\mathbf{B u}
$$

where 


$$
\mathbf{A}(\mathbf{X})=\left[\begin{array}{cccc}
0 & 0 & 1 & 0 \\
0 & 0 & 0 & 1 \\
-k_{1} & -k_{2} U^{2}-p_{1}(\alpha) & -c_{1} & -c_{2}-q_{1}(\dot{\alpha}) \\
-k_{3} & -k_{4} U^{2}-p_{2}(\alpha) & -c_{3} & -c_{4}-q_{2}(\dot{\alpha})
\end{array}\right], \mathbf{B}=\left[\begin{array}{cc}
0 & 0 \\
0 & 0 \\
b_{33} & b_{34} \\
b_{43} & b_{44}
\end{array}\right], \quad \mathbf{u}=\left[\begin{array}{l}
\beta \\
\gamma
\end{array}\right]
$$

and the coefficients in the above equation are defined as

$$
\begin{gathered}
d=m_{T} I_{\alpha}-\left(m_{W} x_{\alpha} b\right)^{2}, k_{1}=I_{\alpha} k_{h} / d, k_{2}=\left(I_{\alpha} \rho b s c_{l \alpha}+m_{W} x_{\alpha} b^{3} \rho s c_{m \alpha}\right) / d, \\
k_{3}=-m_{W} x_{\alpha} b k_{h} / d, k_{4}=-\left(m_{W} \rho s x_{\alpha} b^{2} c_{l \alpha}+m_{T} \rho s b^{2} c_{m \alpha}\right) / d, p_{1}(\alpha)=-m_{W} x_{\alpha} b k_{\alpha}(\alpha) / d, \\
p_{2}(\alpha)=m_{T} k_{\alpha}(\alpha) / d, c_{1}=\left[I_{\alpha}\left(c_{h}+\rho s U b c_{l \alpha}\right)+m_{W} \rho s U x_{\alpha} b^{3} c_{m \alpha}\right] / d, \\
c_{2}=\left[I_{\alpha} \rho s U b^{2} c_{l \alpha}(1 / 2-a)+m_{W} x_{\alpha} \rho s U b^{4} c_{m \alpha}(1 / 2-a)\right] / d, \\
c_{4}=-m_{W}\left(x_{\alpha} b c_{h}+x_{\alpha} \rho U b^{2} c_{l \alpha}+\rho U b^{2} c_{m \alpha}\right) / d, \\
\left.c_{W} x_{\alpha} \rho U b^{3} c_{l \alpha}(1 / 2-a)-m_{T} \rho U b^{3} c_{m \alpha}(1 / 2-a)\right] / d, q_{1}(\dot{\alpha})=m_{W} x_{\alpha} b c_{\alpha}(\dot{\alpha}) / d, \\
q_{2}(\dot{\alpha})=m_{T} c_{\alpha}(\dot{\alpha}) / d, b_{33}=-U^{2} \rho s\left(I_{\alpha} b c_{l \beta}+m_{W} x_{\alpha} b^{3} \bar{c}_{m \beta}\right) / d, \\
b_{34}=-U^{2} \rho s\left(I_{\alpha} b c_{l \gamma}+m_{W} x_{\alpha} b^{3} s \bar{c}_{m \gamma}\right) / d, b_{43}=U^{2} \rho s\left(m_{W} x_{\alpha} b^{2} c_{l \beta}+m_{T} b^{2} \bar{c}_{m \beta}\right) / d, \\
b_{44}=U^{2} \rho s\left(m_{W} x_{\alpha} b^{2} c_{l \gamma}+m_{T} b^{2} \bar{c}_{m \gamma}\right) / d .
\end{gathered}
$$

\section{Adaptive Control of Feedback Linearization}

Both partial and full feedback linearization methods have been used for the nonlinear aeroelastic control in a series of references [38]. In this section, an adaptive control law is derived based on partial feedback. First an output function is defined as follows:

$$
y=\alpha=g(\mathbf{X})=\left[\begin{array}{llll}
0 & 1 & 0 & 0
\end{array}\right] \mathbf{X}
$$

By defining the following state transformation

$$
\begin{aligned}
& z_{1}=y=x_{2} \\
& z_{2}=\dot{y}=x_{4} \\
& z_{3}=x_{1} \\
& z_{4}=b_{4} x_{3}-b_{3} x_{4}
\end{aligned}
$$

the subsystem of $\left(\begin{array}{ll}z_{1} & z_{2}\end{array}\right)$ may be expressed as

$$
\left\{\begin{array}{c}
\dot{z}_{1}=z_{2} \\
\dot{z}_{2}=R(Z)+\sum_{i=1}^{m} c_{i} N_{1}\left(\dot{\alpha}^{i}\right)+\sum_{i=1}^{n} k_{i} N_{2}\left(\alpha^{i}\right)+b_{4} \beta
\end{array}\right.
$$

where $R(\mathbf{Z})$ is a linear function of the state variable $\mathbf{Z}, N_{1}\left(\dot{\alpha}^{i}\right)$ and $N_{2}\left(\alpha^{i}\right)$ are the terms related to 
nonlinear damping and stiffness.

When uncertain parameters in both pitch stiffness and damping are expressed in the form of parameter estimations, the control law for TE control surface may be written as

$$
\beta=\frac{-1}{b_{4}}\left(R(\mathbf{Z})+\sum_{i=1}^{m} \hat{c}_{i} N_{1}\left(\dot{\alpha}^{i}\right)+\sum_{i=1}^{n} \hat{k}_{i} N_{2}\left(\alpha^{i}\right)-v\right)
$$

where $\mathrm{v}$ is design input yet to be determined. It is noted that the internal dynamics subsystem of $\left(\begin{array}{ll}z_{3} & z_{4}\end{array}\right)$ is not affected by the input v, and its stability is discussed in Ref. [26, 27].

Substituting Eq. (11) into the Eq. (10), we have

$$
\left\{\begin{array}{c}
\dot{z}_{1}=z_{2} \\
\dot{z}_{2}=\sum_{i=1}^{m}\left(c_{i}-\hat{c}_{i}\right) N_{1}\left(\dot{\alpha}^{i}\right)+\sum_{i=1}^{n}\left(k_{i}-\hat{k}_{i}\right) N_{2}\left(\alpha^{i}\right)+v
\end{array}\right.
$$

In order to derive a parameter update law, the following Lyapunov function is considered

$$
V=\frac{1}{2}\left[\begin{array}{ll}
z_{1} & z_{2}
\end{array}\right]\left[\begin{array}{l}
z_{1} \\
z_{2}
\end{array}\right]+\frac{1}{2}\left[\begin{array}{cc}
\tilde{\mathbf{C}} & \tilde{\mathbf{K}}
\end{array}\right]\left[\begin{array}{c}
\tilde{\mathbf{C}} \\
\tilde{\mathbf{K}}
\end{array}\right]
$$

where $\tilde{\mathbf{C}}$ and $\tilde{\mathbf{K}}$ are the estimation errors defined as $[\tilde{\mathbf{C}}]=\left[c_{i}-\hat{c}_{i}\right]_{m \times 1},[\tilde{\mathbf{K}}]=\left[k_{i}-\hat{k}_{i}\right]_{n \times 1}$. After differentiating Eq. (13) along Eq. (12), we obtain

$$
\begin{aligned}
\dot{V} & =\left[\begin{array}{ll}
z_{1} & z_{2}
\end{array}\right]\left[\begin{array}{l}
\dot{z}_{1} \\
\dot{z}_{2}
\end{array}\right]+\left[\begin{array}{ll}
\tilde{\mathbf{C}}^{\mathbf{T}} & \tilde{\mathbf{K}}^{\mathbf{T}}
\end{array}\right]\left[\begin{array}{c}
\dot{\tilde{\mathbf{C}}} \\
\dot{\tilde{\mathbf{K}}}
\end{array}\right] \\
& =\left[\begin{array}{ll}
z_{1} & z_{2}
\end{array}\right] \mathbf{D}\left[\begin{array}{l}
z_{1} \\
z_{2}
\end{array}\right]+z_{2}\left[\begin{array}{ll}
\tilde{\mathbf{C}}^{\mathbf{T}} & \tilde{\mathbf{K}}^{\mathbf{T}}
\end{array}\right] \mathbf{N}+\left[\begin{array}{ll}
\tilde{\mathbf{C}}^{\mathbf{T}} & \tilde{\mathbf{K}}^{\mathbf{T}}
\end{array}\right]\left[\begin{array}{c}
\dot{\tilde{\mathbf{C}}} \\
\dot{\tilde{\mathbf{K}}}
\end{array}\right]
\end{aligned}
$$

where $\mathbf{D}$ is a negative-definitive matrix, and $\mathbf{N}$ is the state variable related to nonlinear terms defined as

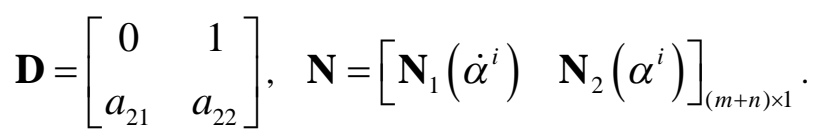

If the following equation is true

$$
\left[\begin{array}{cc}
\dot{\tilde{\mathbf{C}}}^{T} & \dot{\tilde{\mathbf{K}}}^{T}
\end{array}\right]^{T}=-z_{2} \mathbf{N}
$$

then $\dot{V} \leq 0$. The stability of Eq. (12) is guaranteed by the invariant manifold theorem of La Salle and Lefschetz [39]. As the parameters for a given structure are unchanged, we have

$$
\left[\begin{array}{ll}
\dot{\mathbf{C}}^{T} & \dot{\mathbf{K}}^{T}
\end{array}\right]^{T}=0
$$

Therefore the parameter estimate update law is obtained as follows

$$
\left[\begin{array}{ll}
\dot{\hat{\mathbf{C}}}^{T} & \dot{\hat{\mathbf{K}}}^{T}
\end{array}\right]^{T}=-\left[\begin{array}{cc}
\dot{\tilde{\mathbf{C}}}^{T} & \dot{\tilde{\mathbf{K}}}^{T}
\end{array}\right]^{T}=z_{2} \mathbf{N}
$$

Finally, it should be emphasized that the control law may be used only if the zero dynamics of $\left(\begin{array}{ll}z_{3} & z_{4}\end{array}\right)$ 
is stable.

\section{Structured Model Reference Adaptive Control}

Structured model reference (SMR) adaptive control method has been developed for a special type of structure by Akella and Junkins [40], and used for flutter suppression of an aeroelastic system [41]. In this section, we derive a SMR adaptive control law for the wing section when both LE and TE control surfaces are activated as shown in Fig. 1. By introducing the state variables $\mathbf{X}=\left[\begin{array}{ll}\mathbf{X}_{1} & \mathbf{X}_{2}\end{array}\right]^{T}$, where, $\mathbf{X}_{1}=\left[\begin{array}{ll}h & \alpha\end{array}\right]^{T}$, $\mathbf{X}_{2}=\left[\begin{array}{ll}\dot{h} & \dot{\alpha}\end{array}\right]^{T}$, Eq.(6) may be partitioned into two subsystems

$$
\begin{aligned}
& \dot{\mathbf{X}}_{1}=\mathbf{X}_{2} \\
& \dot{\mathbf{X}}_{2}=\overline{\mathbf{A}}(\mathbf{x}) \mathbf{x}+\overline{\mathbf{B}} \mathbf{u}
\end{aligned}
$$

where

$$
\overline{\mathbf{A}}(\mathbf{X})=\left[\begin{array}{cccc}
-k_{1} & -k_{2} U^{2}-p_{1}(\alpha) & -c_{1} & -c_{2}-q_{1}(\dot{\alpha}) \\
-k_{3} & -k_{4} U^{2}-p_{2}(\alpha) & -c_{3} & -c_{4}-q_{2}(\dot{\alpha})
\end{array}\right], \overline{\mathbf{B}}=\left[\begin{array}{ll}
b_{11} & b_{12} \\
b_{21} & b_{22}
\end{array}\right]
$$

The parameters in matrixes A and B are defined in Eq. (7).

Here we still consider both stiffness and damping parametric uncertainties in pitch. Then the second equation of Eq. (18) may be rewritten as

$$
\dot{\mathbf{X}}_{2}=\mathbf{A}_{l} \mathbf{X}+\mathbf{U}_{l} \mathbf{C}+\mathbf{U}_{2} \mathbf{K}+\overline{\mathbf{B}} \mathbf{u}
$$

where matrix $\quad \mathbf{A}_{l}$ contains the known parameters of matrix $\overline{\mathbf{A}}(x) ; \mathbf{U}_{1}$ and $\mathbf{U}_{2}$ are matrixes related to nonlinear stiffness and damping defined as

$$
\mathbf{U}_{1}=\left[\begin{array}{c}
-\frac{m_{W} x_{\alpha} b c_{i} \dot{\alpha}^{i}}{d} \\
\frac{m_{T} c_{i} \dot{\alpha}^{i}}{d}
\end{array}\right]_{2 \times m}, \mathbf{U}_{2}=\left[\begin{array}{c}
-\frac{m_{W} x_{\alpha} b k_{i} \alpha^{i}}{d} \\
\frac{m_{T} k_{i} \alpha^{i}}{d}
\end{array}\right]_{2 \times n}
$$

$\mathbf{C}$ and $\mathbf{K}$ are state variables of uncertain parameters

$$
\mathbf{C}=\left[c_{i}\right]_{m \times 1}, \mathbf{K}=\left[k_{i}\right]_{n \times 1}
$$

In order to derive the MRA control law, a reference trajectory $\overline{\mathbf{X}}_{1}$ is introduced. The error is defined as $\mathbf{e}=\mathbf{X}_{1}-\overline{\mathbf{X}}_{1}$ and the error dynamic equation is written as follows:

$$
\ddot{\mathbf{e}}+\mathbf{C}_{e} \dot{\mathbf{e}}+\mathbf{K}_{e} \mathbf{e}=0
$$

where $\mathbf{C}_{e}$ and $\mathbf{K}_{e}$ are constant matrices to be chosen. From Eq. (20) and Eq. (21), we get

$$
\mathbf{A}_{l} \mathbf{X}+\mathbf{U}_{1} \mathbf{C}+\mathbf{U}_{2} \mathbf{K}+\mathbf{B u}=\ddot{\overline{\mathbf{X}}}_{1}-\mathbf{C}_{e}\left(\dot{\mathbf{X}}_{1}-\dot{\overline{\mathbf{X}}}_{1}\right)-\mathbf{K}_{e}\left(\mathbf{X}_{1}-\overline{\mathbf{X}}_{1}\right)
$$

If the parameter estimations $\hat{C}$ and $\hat{K}$ are given, the following control law can be obtained 


$$
u=\mathbf{B}^{-1}\left[\ddot{\mathbf{X}}_{1}-\mathbf{C}_{e}\left(\dot{\mathbf{X}}_{1}-\dot{\mathbf{X}}_{1}\right)-\mathbf{K}_{e}\left(\mathbf{X}_{1}-\overline{\mathbf{X}}_{1}\right)-\mathbf{A}_{l} \mathbf{X}-\mathbf{U}_{1} \hat{\mathbf{C}}-\mathbf{U}_{2} \hat{\mathbf{K}}\right]
$$

By substituting the control law into Eq. (20), the error dynamic system becomes

$$
\ddot{\mathbf{e}}+\mathbf{C}_{e} \dot{\mathbf{e}}+\mathbf{K}_{e} \mathbf{e}=-\mathbf{U}_{1} \tilde{\mathbf{C}}-\mathbf{U}_{2} \tilde{\mathbf{K}}
$$

where $\tilde{\mathbf{C}}$ and $\tilde{\mathbf{K}}$ are the error state variables as defined earlier. By defining the state variable as $\mathbf{E}=\left[\begin{array}{ll}\mathbf{e} & \dot{\mathbf{e}}\end{array}\right]^{T}$, Eq. (24) may be rewritten in state-space form as follows

$$
\dot{\mathbf{E}}=\left[\begin{array}{cc}
\mathbf{0}_{2 \times 2} & \mathbf{I}_{2 \times 2} \\
-\mathbf{K}_{e} \mathbf{I}_{2 \times 2} & -\mathbf{C}_{e} \mathbf{I}_{2 \times 2}
\end{array}\right] \mathbf{E}+\left[\begin{array}{c}
\mathbf{0}_{2 \times 1} \\
-\mathbf{U}_{1} \tilde{\mathbf{C}}-\mathbf{U}_{2} \tilde{\mathbf{K}}
\end{array}\right]=\mathbf{A}_{e} \mathbf{E}+\mathbf{B}_{e}
$$

In order to derive the parameter update law, a Lyapunov function is defined as follows

$$
V=\mathbf{E}^{T} \mathbf{P E}+\operatorname{tr}\left[\left[\begin{array}{ll}
\tilde{\mathbf{C}}^{T} & \tilde{\mathbf{K}}^{T}
\end{array}\right] \boldsymbol{\Gamma}^{-1}\left[\begin{array}{ll}
\tilde{\mathbf{C}}^{T} & \tilde{\mathbf{K}}^{T}
\end{array}\right]^{T}\right]
$$

where $\boldsymbol{\Gamma}$ is a positive-definite matrix; $\mathbf{P}$ is a symmetric positive-definite matrix determined by the following Lyapunov equation:

$$
\mathbf{A}_{e}^{T} \mathbf{P}+\mathbf{P} \mathbf{A}_{e}=-\mathbf{Q}
$$

where matrix $\mathbf{A}_{\mathrm{e}}$ is stable, and $\mathbf{Q}$ is a selected symmetric positive-definite matrix.

Differentiating the Lyapunov function along Eq. (25) gives

$$
\begin{aligned}
& \dot{V}=\dot{\mathbf{E}}^{T} \mathbf{P E}+\mathbf{E}^{T} \mathbf{P} \dot{\mathbf{E}}+2 \operatorname{tr}\left[\left[\begin{array}{ll}
\tilde{\mathbf{C}}^{T} & \tilde{\mathbf{K}}^{T}
\end{array}\right] \Gamma^{-1}\left[\begin{array}{ll}
\dot{\tilde{\mathbf{C}}}^{T} & \dot{\tilde{\mathbf{K}}}^{T}
\end{array}\right]^{T}\right] \\
& =-\mathbf{E}^{T} \mathbf{Q E}-2 \mathbf{E}^{T} \mathbf{P} \mathbf{B}_{e}+2 \operatorname{tr}\left[\left[\begin{array}{cc}
\tilde{\mathbf{C}}^{T} & \tilde{\mathbf{K}}^{T}
\end{array}\right] \Gamma^{-1}\left[\begin{array}{cc}
\dot{\tilde{\mathbf{C}}}^{T} & \dot{\tilde{\mathbf{K}}}^{T}
\end{array}\right]^{T}\right]
\end{aligned}
$$

As we know, the following equation is true

$$
\mathbf{E}^{T} \mathbf{P} \mathbf{B}_{e}=\operatorname{tr}\left[\mathbf{E}^{T} \mathbf{P} \mathbf{B}_{e}\right]=-\operatorname{tr}\left[\left[\begin{array}{ll}
\tilde{\mathbf{C}}^{T} & \tilde{\mathbf{K}}^{T}
\end{array}\right]\left[\begin{array}{ll}
\mathbf{U}^{T} & \mathbf{U}^{T}{ }_{2}
\end{array}\right]^{T} \mathbf{P}_{h}^{T} \mathbf{E}\right]
$$

where $\mathbf{P}_{\mathrm{h}}$ is a sub-matrix of $\mathbf{P}$. If we assume

$$
\boldsymbol{\Gamma}^{-1}\left[\begin{array}{cc}
\dot{\tilde{\mathbf{C}}}^{T} & \dot{\tilde{\mathbf{K}}}^{T}
\end{array}\right]^{T}=-\left[\begin{array}{ll}
\mathbf{U}^{T} & \mathbf{U}^{T}{ }_{2}
\end{array}\right]^{T} \mathbf{P}_{h}^{T} \mathbf{E}
$$

then $\dot{V} \leq 0$ since $\mathbf{Q}$ is a positive-definite matrix. The stability of Eq. (25) is guaranteed by the invariant manifold theorem of La Salle and Lefschetz [39]. Sine the structure properties do not change, we have $\left[\begin{array}{ll}\dot{\mathbf{C}}^{T} & \dot{\mathbf{K}}^{T}\end{array}\right]^{T}=0$. From Eq. (30), the parameter estimate update law can be obtained as

$$
\left[\begin{array}{cc}
\dot{\hat{\mathbf{C}}}^{T} & \dot{\hat{\mathbf{K}}}^{T}
\end{array}\right]^{T}=-\left[\begin{array}{cc}
\dot{\tilde{\mathbf{C}}}^{T} & \dot{\tilde{\mathbf{K}}}^{T}
\end{array}\right]^{T}=\boldsymbol{\Gamma}\left[\begin{array}{cc}
\mathbf{U}^{T} & \mathbf{U}^{T}{ }_{2}
\end{array}\right]^{T} \mathbf{P}_{h}^{T} \mathbf{E}
$$

\section{Example Results and Discussion}

In this section, numerical examples would be given to verify the control laws derived in section 3 and 4. For each example, open-loop flutter characters were first present to help the aeroelastic system being considered to be understood.

\subsection{Example 1}

For the wing section with single TE control surface, the model and parameters used in Ref. [27] were chosen 
in this case study and listed in table 1 . The coefficients of nonlinear pitch stiffness used in the simulation are $\left\{k_{i}\right\}$ $=\left[\begin{array}{ll}6.833 & 9.967667 .685 \\ 26.569 & -5087.931\end{array}\right]$. This nonlinear stiffness relationship was approximated based on experimental measured data in Ref. [27], and was shown in Fig. 2. The pitch damping coefficient $c_{\alpha}=0.036$.

The response of the open-loop aeroelastic system is dependent on the flow velocity and initial conditions. Given a set of initial conditions, the response is convergent when the flow velocity is smaller than a critical value (flutter speed). And LCO will occur when the flow velocity is higher than flutter speed. With the initial conditions $h(0)=0.01 \mathrm{~m}, \alpha(0)=0.1 \mathrm{rad}$, and $\dot{h}(0)=\dot{\alpha}(0)=0$, Fig. 3 shows the plunge and pitch responses for the flow velocity $U=7.91 \mathrm{~m} / \mathrm{s}$ and $U=7.92 \mathrm{~m} / \mathrm{s}$ separately. The responses are totally different, which means that the flutter speed is $7.92 \mathrm{~m} / \mathrm{s}$ for the special initial conditions. In order to investigate the effect of initial conditions on flutter speed, flutter boundaries on initial pitch angle were obtained. With initial plunge and pitch velocities $\dot{h}(0)=\dot{\alpha}(0)=0$, Fig. 4 gives three flutter boundaries for three different initial plunge displacements. We find that flutter boundary is symmetric about $\alpha(0)=0$ axis when $h(0)=0$. And the increasing of $h(0)$ reduces the effect of $\alpha(0)$ on flutter speed. The flutter speed decrease from $11.6 \mathrm{~m} / \mathrm{s}$ to 7.9 $\mathrm{m} / \mathrm{s}$ with $\alpha(0)$ increasing from 0 to $\pm 0.2 \mathrm{rad}$. When $h(0)=0.01$, the maximum flutter speed becomes $10.5 \mathrm{~m} / \mathrm{s}$. And it continues decrease to $8.9 \mathrm{~m} / \mathrm{s}$ when $h(0)=0.05$.

Now the feedback linearization adaptive control law Eq. (11) and parameter estimate update law Eq. (17) were considered to suppress the LCOs described above. The initial conditions were chosen as $h(0)=0.01 \mathrm{~m}$, $\alpha(0)=0.1 \mathrm{rad}, \dot{h}(0)=\dot{\alpha}(0)=0$. It is noted in this case that the pitch damping is still linear, which is the same with Ref. [27]. In the nonlinear adaptive controller design however, it was modeled as a third-order polynomial, and so $\left\{c_{i}\right\}=\left[\begin{array}{lll}0.036 & 0 & 0\end{array}\right]$. The eight initial estimations of both stiffness and damping uncertainty parameters were set to zero. In order to show the effect of damping uncertainty on the closed-loop responses, the simulations of adaptive control with and without damping uncertainty were carried out in the same time.

Figure 5 shows the time histories of the closed-loop system in plunge, pitch, and control surface deflection for free stream velocity $U=16 \mathrm{~m} / \mathrm{s}$. We find that the aerodynamic system is stable in both the two cases, which indicates that the adaptive control law is effective to control the LCOs. Furthermore, it is obvious that when the damping uncertainty was taken into account, the system responses were suppressed to converge in less period of time. As the adaptive control law is designed based the output of pitch angle, considering the damping uncertainty dramatically reduces the convergence time of pitching response from about $3 \mathrm{~s}$ to less than $0.5 \mathrm{~s}$. For the plunge response, the peak values with damping uncertainty are smaller than the ones without uncertainty. In this case however, it is noted that the required maximum TE control deflection is about $0.65 \mathrm{rad}(37 \mathrm{deg})$ as shown in Fig. 5c, which is impractical to implement. So another case was performed with the control surface deflection was limited to $\pm 15 \mathrm{deg}$, while the other conditions remain unchanged. Simulation results are presented in Fig. 6. All the states converge to zero after a transitory vibration. The flap deflection limit causes a slightly longer convergent time to the closed-loop system with damping uncertainty. But it still converges faster than the system without damping uncertainty, especially the pitch variable.

\subsection{Example 2}

In this example, the wing section illustrated in Fig. 1 was considered again to simulate the flutter suppression by using both TE and LE control surfaces. Reference [31] presented an experimental wing section with both TE and LE control surfaces. The system parameters are listed in table 2. A third order polynomial model of the stiffness is built from static measurements on the nonlinear pitch cam. And the coefficients of nonlinear pitch

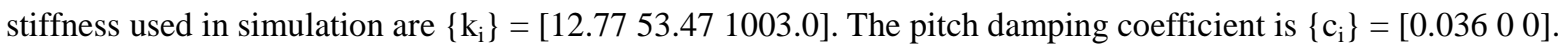

The open-loop system was investigated first. Similar with example 1, the flutter speed is dependent on the initial conditions. Numbers of simulations were performed with different initial conditions. We find that with 
initial pitch angle $\alpha(0)$ and plunge displacement $h(0)$ vary in the field of $[0.001,0.5]$, the flutter speed may changes from $10.6 \mathrm{~m} / \mathrm{s}$ to $11.4 \mathrm{~m} / \mathrm{s}$. Compared with example 1 , the flutter speed of example 2 is less sensitive on the initial conditions. That may because the pitch spring of example 2 is stiffer, as shown in Fig. 2. For the initial conditions $h(0)=0.01 \mathrm{~m}, \alpha(0)=0.1 \mathrm{rad}$, and $\dot{h}(0)=\dot{\alpha}(0)=0$, the critical flutter velocity is $10.7 \mathrm{~m} / \mathrm{s}$. When free stream velocity is lower than the flutter speed, all the 4 states converge to zero quickly. Figure 7 shows the time histories and phase diagrams of convergent responses for $U=10.0 \mathrm{~m} / \mathrm{s}$. And Fig. 8 presents a case of LCOs for $\mathrm{U}=15.0 \mathrm{~m} / \mathrm{s}$.

The SMR adaptive control law expressed in Eq. (23) and parameter estimate update law Eq. (31) were applied to control the LCOs of the aeroelastic system with both TE and LE control surfaces. The initial conditions keep unchanged, and the 6 initial estimations of the uncertainty parameters were set to be zero. The simulation was run at a free stream velocity $U=15 \mathrm{~m} / \mathrm{s}$ beyond the system flutter velocity $(10.7 \mathrm{~m} / \mathrm{s})$. Both the LE and TE control surface deflections were limited up to $\pm 15 \mathrm{deg}$ and actuated at time $\mathrm{t}=3 \mathrm{~s}$. Figure 9 shows the response time histories of the closed-loop system in plunging, pitching, TE, and LE deflection. It is clear that the responses in pitch and plunge are damping out in less than $2 \mathrm{~s}$. Further extensive simulations were performed for higher free stream velocity. It was noted that when the velocity approached $U=28.3 \mathrm{~m} / \mathrm{s}$, the controller became less effective in suppressing the limit circle oscillation.

The effect of damping uncertainty has been investigated. In lower free stream velocity range, the two closed-loop aeroelastic systems with and without damping uncertainty have almost the same behavior and response. When the free stream velocity approaches the flutter speed of the closed-loop system however, their closed-loop system responses are significantly different. Fig. 10 shows an case at the velocity U=28 m/s. The flutter speed of the closed-loop system without damping uncertainty is $U=27.7 \mathrm{~m} / \mathrm{s}$, which is below $U=28.3 \mathrm{~m} / \mathrm{s}$. Obviously, flutter speed is dependent on the control surface deflection limits. Figure 11 shows the difference of flutter speeds between the systems with and without damping uncertainty. We find that with the control surface maximum deflection increasing from $10 \mathrm{deg}$ to $20 \mathrm{deg}$, the closed-loop aeroelastic system including damping uncertainty has higher flutter speeds.

\section{Conclusions}

In this paper, the effect of damping uncertainty on the controller design and effectiveness for flutter suppression of a wing section model has been investigated. Open-loop flutter characters of the two wing section haven been studied firstly. Then, two adaptive control laws for a 2-D nonlinear aeroelastic airfoil with stiffness and damping uncertainties in pitch have been derived. For the wing section of a single trailing-edge control only, an adaptive control law was designed based on partial feedback linearization. Simulation results show that the damping uncertainty has positive effect on the control effectiveness. The closed-loop system considering damping uncertainty has quicker response to control and more effectiveness in flutter suppression. For the wing section having both LE and TE control surfaces, a SMR adaptive control law was derived. Simulation results show that the SMR adaptive controller considering the damping uncertainty is also effective in low free stream velocity range. In higher velocity however, the effectiveness of the controller reduces although the flutter velocity of the closed-loop system is greater due to the damping uncertainty.

\section{Acknowledgments}

The authors would like to acknowledge the financial support of the National Nature Science Grant of China: 90916006 and the EC funding for the EU FP7 collaborative project SADE. 


\section{References}

[1] B.H.K. Lee, S.J. Price, Y.S. Wong, Nonlinear Aeroelastic Analysis of Airfoil: Bifurcation and Chaos, Progress in Aerospace Science, 35 (3) (1999) 205-334.

[2] E.H. Dowell, J. Edwards, T. Strganac, Nonlinear Aeroelasticity, Journal of Aircraft, 40 (5) (2003) 857-874.

[3] L. Djayapertapa, C.B. Allen, S.P. Fiddes, Two-dimensional transonic aeroservoelastic computations in the time domain, International Journal for Numerical Methods in Engineering 52 (2001) 1355-1377.

[4] L. Djayapertapa, C.B. Allen, Aeroservoelastic simulation by time-marching, Aeronautical Journal 105 (2001) 667-678.

[5] L. Djayapertapa, C.B. Allen, Numerical simulation of transonic flutter suppression by active control. AIAA Paper 2002-2713, 20th Applied Aerodynamics Conference, St Louis, 2002.

[6] C.B. Allen, C.L. Fenwick, N.V. Taylor, L. Djayapertapa, Investigation of flutter suppression by active control. AIAA Paper 2003-3510, 21st AIAA Applied Aerodynamics Conference, Florida, June 2003.

[7] C.B. Allen, N.V. Taylor, C.L. Fenwick, A.L. Gaitonde, D.P. Jones, A Comparison of Full Non-Linear and Reduced Order Aerodynamic Models in Control Law Design for Active Flutter Suppression, International Journal for Numerical Methods in Engineering 64 (2005) 1628-1648.

[8] D. Li, J. Xiang, Chaotic Motions of an Airfoil with Cubic Nonlinearity in Subsonic Flow, Journal of Aircraft, 45 (4) (2008) 1457-1460.

[9] D.M. Tang, E.H. Dowell, Aeroelastic airfoil with free play at angle of attack with gust excitation, AIAA Journal 48 (2) (2010) 427-442

[10] M.D. Conner, D.M. Tang, E.H Dowell, L.N. Virgin, Nonlinear Behavior of a Typical Airfoil Section with Control Surface Freeplay: A Numerical and Experimental Study, Journal of Fluids and Structures 11 (1) (1997) 89-109.

[11] D.M. Tang, P.G. Henri, E.H. Dowell, Study of Airfoil Gust Response Alleviation Using an ElectroMagnetic Dry Friction Damper, Part 1: Theory, Journal of Sound and Vibration (269) (3-5) (2004) 853-874.

[12] J.S. Vipperman, R.L. Clark, M. Conner, E.H. Dowell, Experimental Active Control of a Typical Section Using a Trailing-Edge Flap, Journal of Aircraft 35 (2) (1998) 224-229.

[13] R.L. Clark, E.H. Dowell, K. D. Frampton, Control of a Three-Degree-of-Freedom Airfoil with Limit-Cycle Behavior, Journal of Aircraft 37 (3) (2000) 533-536.

[14] D. Tang, E.H. Dowell, Flutter/LCO suppression for high-aspect ratio wings, The aeronautical Journal 113 (1144) (2009) 409-416.

[15] J.J. Block, T.W. Strganac, Applied Active Control for a Nonlinear Aeroelastic Structure, Journal of Guidance, Control, and Dynamics, 21 (6) (1998) 838-845.

[16] J. Ko, A.J. Kurdila, T.W. Strganac, Nonlinear Control of a Prototypical Wing Section with Torsional Nonlinearity, Journal of Guidance, Control, and Dynamics, 20 (6) (1997) 1181-1189.

[17] J. Ko, T.W. Strganac, A.J. Kurdila, Stability and Control of a Structurally Nonlinear Aeroelastic System, Journal of Guidance, Control, and Dynamics, 21 (5) (1998)718-725.

[18] S.N. Singh, W. Yim, State Feedback Control of an Aeroelastic System with Structural Nonlinear, Aerospace Science and Technology, 7 (1) (2003) 23-31.

[19] M. Tadi, State-Dependent Riccati Equation for Control of Aeroelastic Flutter, Journal of Guidance, Control, and Dynamics, 26 (6) (2003) 914-917.

[20] N. Bhoir, S.N. Singh Control of Unsteady Aeroelastic System via State-Dependent Riccati Equation Method, Journal of Guidance, Control, and Dynamics, 28.(1) (2005) 78-84. 
[21] D. Li, S. Guo, J. Xiang, Aeroelastic dynamic response and control of an airfoil section with control surface nonlinearities, Journal of Sound and Vibration 329 (2010) 4756-4771.

[22] K.W. Lee, S.N. Singh, Global Robust Control of an Aeroelastic System Using Output Feedback, Journal of Guidance, Control, and Dynamics, 30 (1) (2007) 271-275.

[23] C.L. Pettit, Uncertainty Quantification in Aeroelasticity: Recent Results and Research Challenges, Journal of Aircraft 41 (5) (2004) 1217-1229

[24] C.L. Pettit, P.S. Beran, Effects of parametric uncertainty on airfoil limit cycle oscillation, Journal of Aircraft 40 (5) (2003) 1004-1006.

[25] P.S. Beran, C.L. Pettit, D.R. Millman, Uncertainty Quantification of Limit-cycle Oscillations, Journal of Computational Physics 217 (1) (2006) 217-247.

[26] J. Ko, T.W. Strganac, Adaptive Feedback Linearization for the Control of a Typical Wing Section with Structural Nonlinearity, Nonlinear Dynamics, 18 (3) (1999) 289-301.

[27] T.W. Strganac, J. Ko, D.E. Thompson, Identification and Control of Limit Cycle Oscillations in Aeroelastic Systems, Journal of Guidance, Control, and Dynamics, 23 (6) (2000) 1127-1133.

[28] Y. Zeng, S.N. Singh, Output Feedback Variable Structure Adaptive Control of an Aeroelastic System, Journal of Guidance, Control, and Dynamics, 21 (6) (1998) 830-837.

[29] S.N. Singh, M. Brenner, Modular Adaptive Control of a Nonlinear Aeroelastic System, Journal of Guidance, Control, and Dynamics, 26 (3) (2003) 443-451.

[30] R. Zhang, S.N. Singh, Adaptive Output Feedback Control of an Aeroelastic System with Unstructured Uncertainties, Journal of Guidance, Control, and Dynamics, 24 (3) (2001) 502-509.

[31] G. Platanitis, T.W. Strganac, Control of a Nonlinear Wing Section Using Leading-and Trailing-Edge Surfaces, Journal of Guidance, Control, and Dynamics, 27 (1) (2004) 52-58.

[32] G. Platanitis, T.W. Strganac, Suppression of Control Reversal Using Leading- and Trailing-Edge Control Surfaces, Journal of Guidance, Control, and Dynamics, 28 (3) 2005 452-460.

[33] A. Behal, V.M. Rao, P. Marzocca, Adaptive Control for a Nonlinear Wing Section with Multiple Flaps, Journal of Guidance, Control, and Dynamics, 29 (5) (2006) 744-748.

[34] A. Behal, P. Marzocca, V.M. Rao, A. Gnann, Nonlinear Adaptive Control of an Aeroelastic Two-Dimensional Lifting Surface, Journal of Guidance, Control, and Dynamics, 29 (2) (2006) 382-390.

[35] C.M. Lin, W.L. Chin, Adaptive Decoupled Fuzzy Sliding-Model Control of a Nonlinear Aeroelastic System, Journal of Guidance, Control, and Dynamics, 29 (1) (2006) 206-209.

[36] Baranyi, P., Tensor-Product Model-Based Control of Two-Dimensional Aeroelastic System, Journal of Guidance, Control, and Dynamics, 29 (2) (2006) 391-400.

[37] C.C. Marsden, S.J. Price, Transient and Limit Cycle Simulation of a Nonlinear Aeroelastic System, Journal of Aircraft, 44 (1) (2007) 60-70.

[38] A.J. Kurdila, T.W. Strganac, J.L. Junkins, J. Ko, M.R. Akella, Nonlinear Control Methods for High-Energy Limit-Cycle Oscillations, Journal of Guidance, Control, and Dynamics, 24 (1) (2001) 185-192.

[39] J.E. Slotine, W. Li, Applied Nonlinear Control, Prentice-Hall, Englewood Cliffs, NJ, 1991.

[40] M.R. Akella, J.L. Junkins, Structured Model Reference Adaptive Control with Actuator Saturation Limits, AIAA paper 98-4472, 1998.

[41] J. Ko, T.W. Strganac, J.L. Junkins, Structured Model Reference Adaptive Control for a Wing Section with Structural Nonlinearity, Journal of Vibration and Control, 8 (5) (2002) 553-557. 


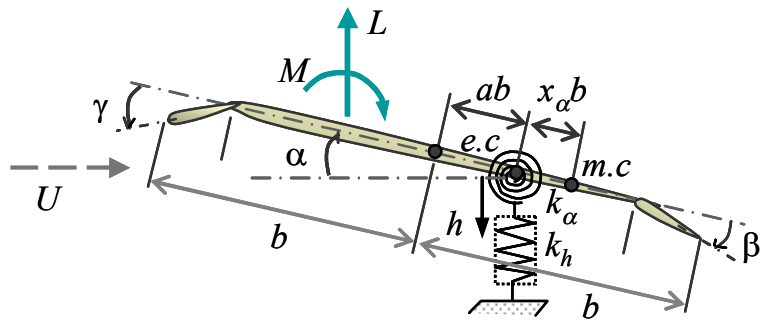

Fig. 1. Aeroelastic model with LE and TE control surfaces. 


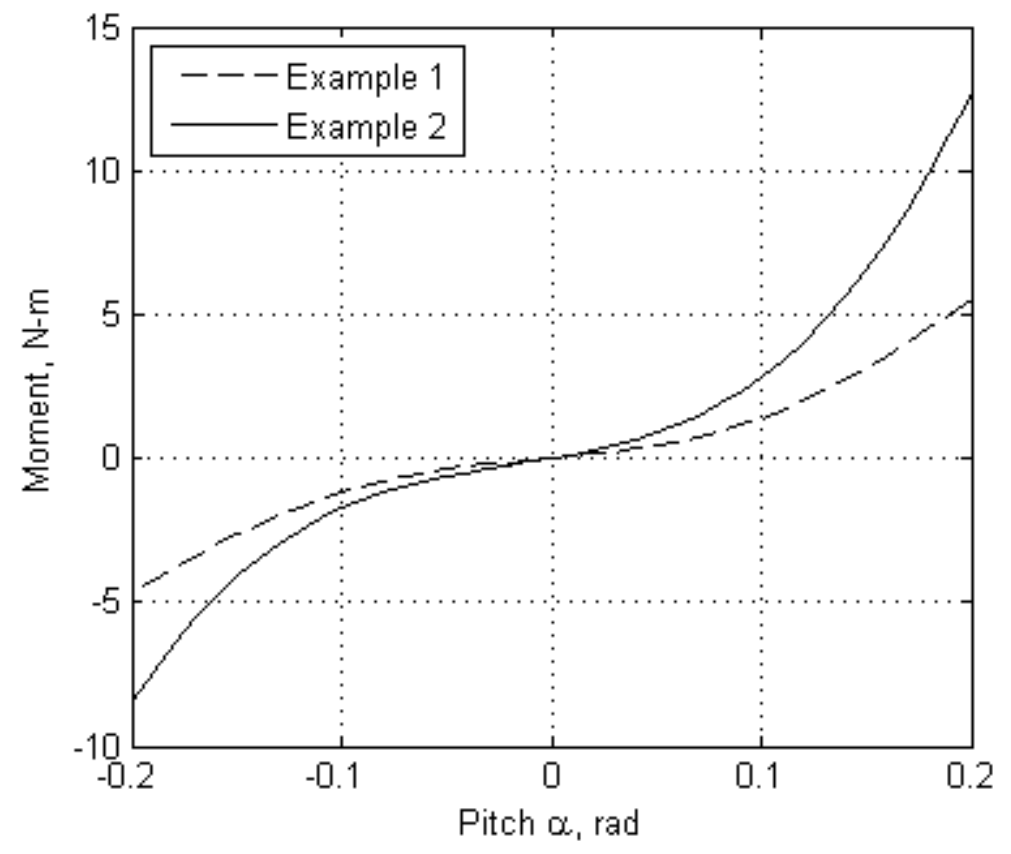

Fig. 2. Nonlinear pitch stiffness (Ref. [27, 31]). 

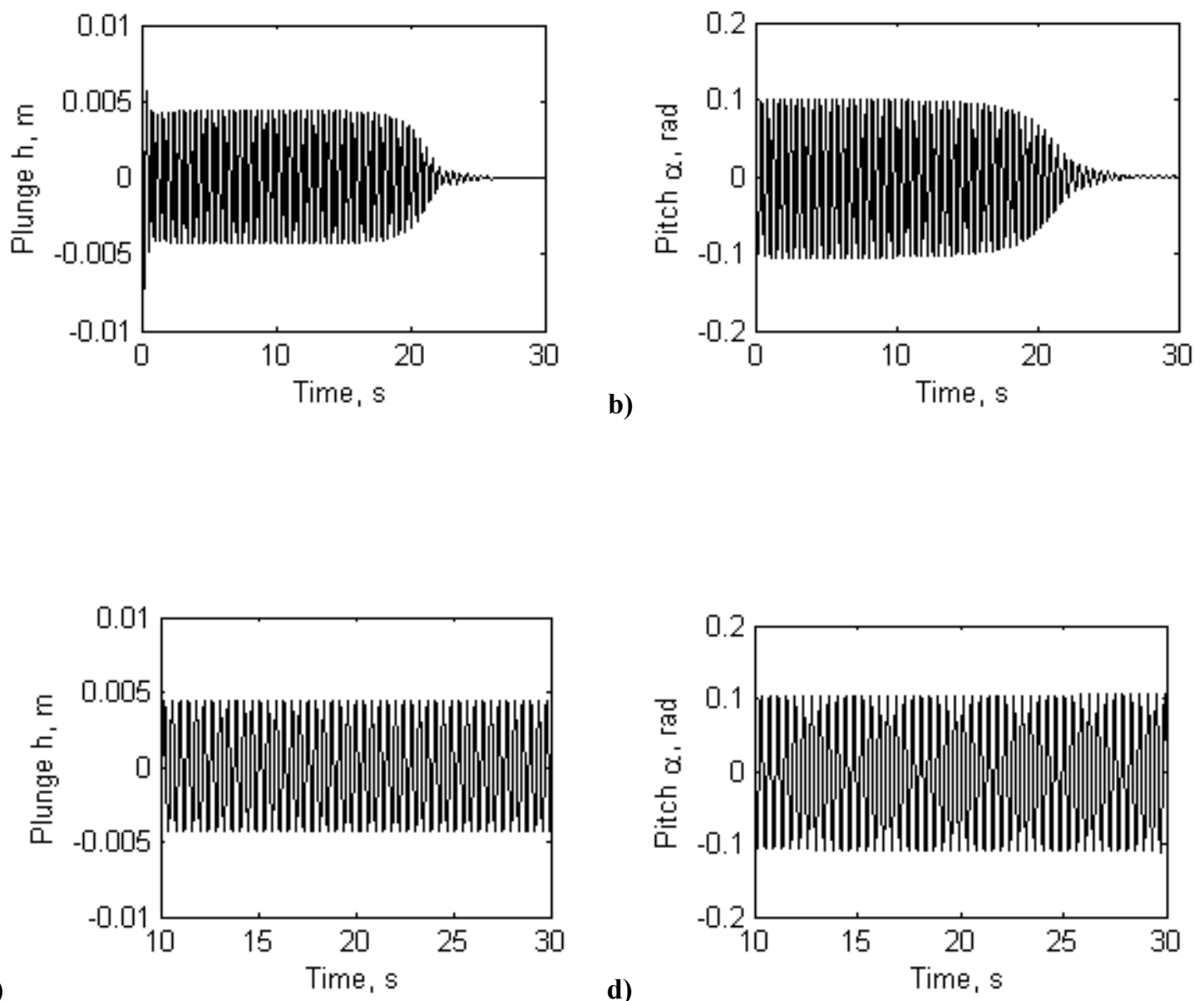

Fig. 3. Time histories of open-loop system for a), b): $U=7.91 \mathrm{~m} / \mathrm{s}$; and c), d): $U=7.92 \mathrm{~m} / \mathrm{s}$. 


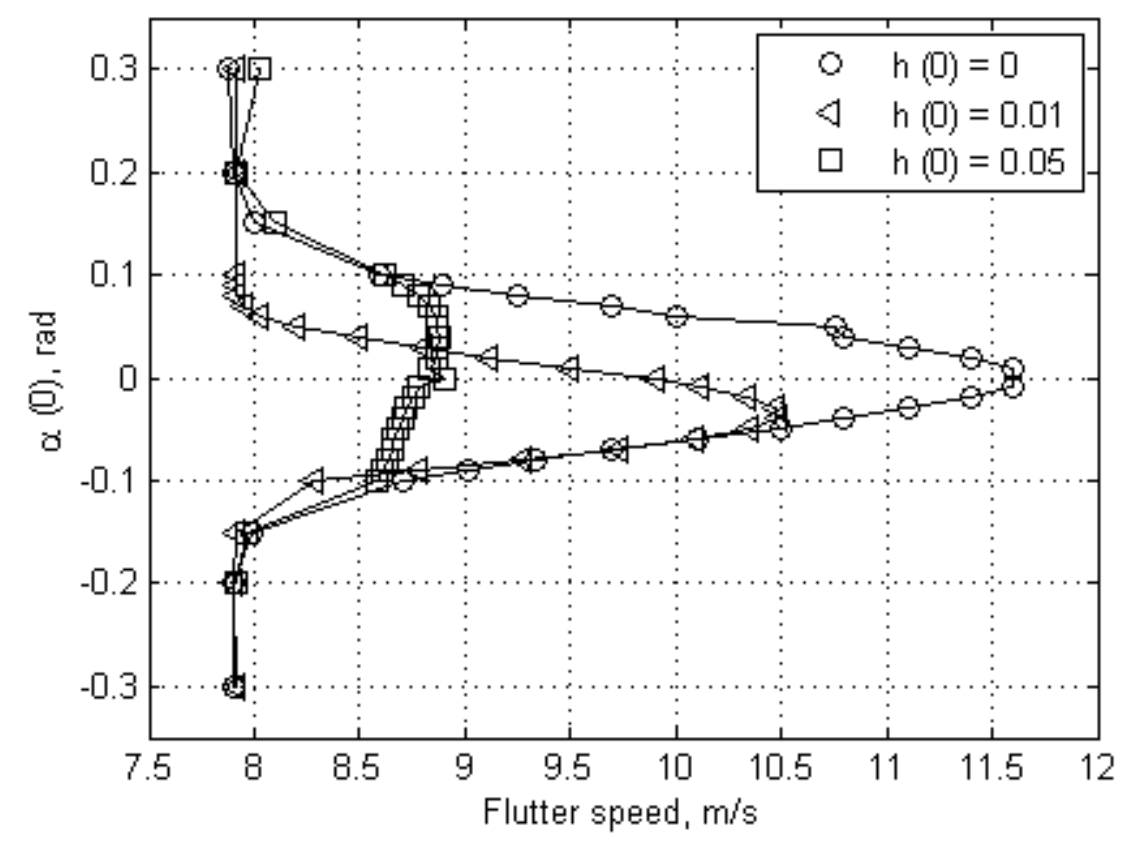

Fig. 4. Flutter boundary on initial pitch angle for $\dot{h}(0)=\dot{\alpha}(0)=0$. 


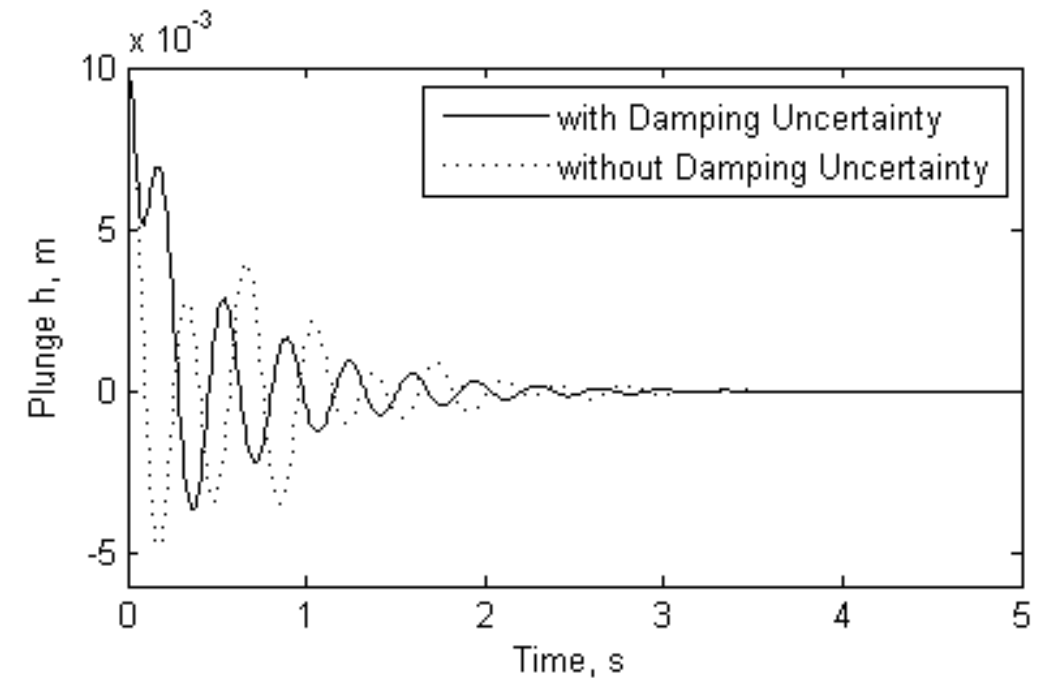

a)

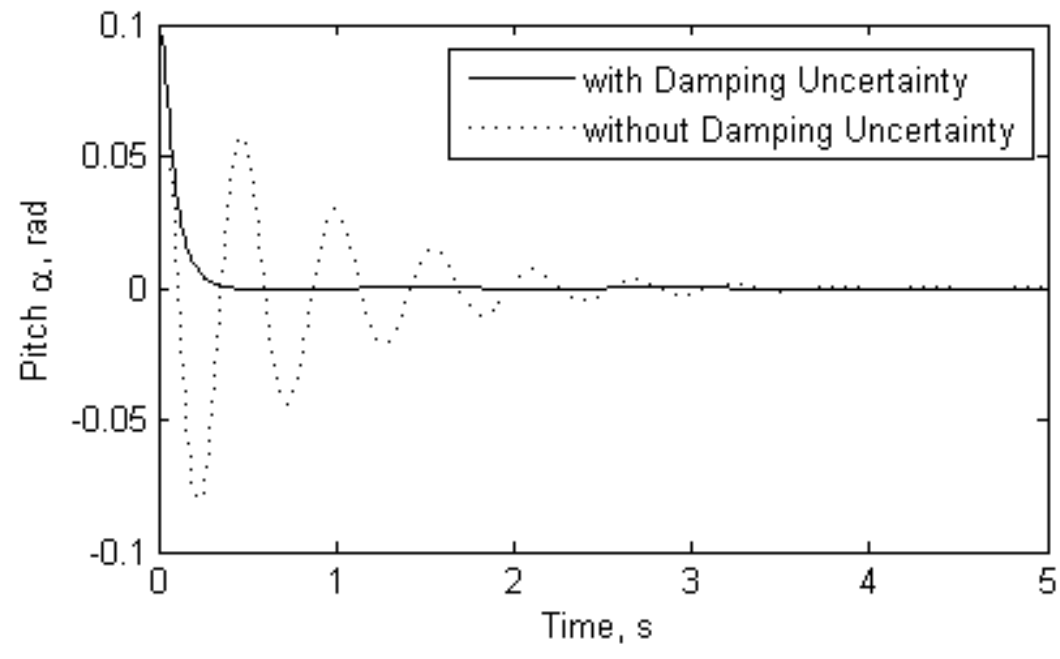

b)

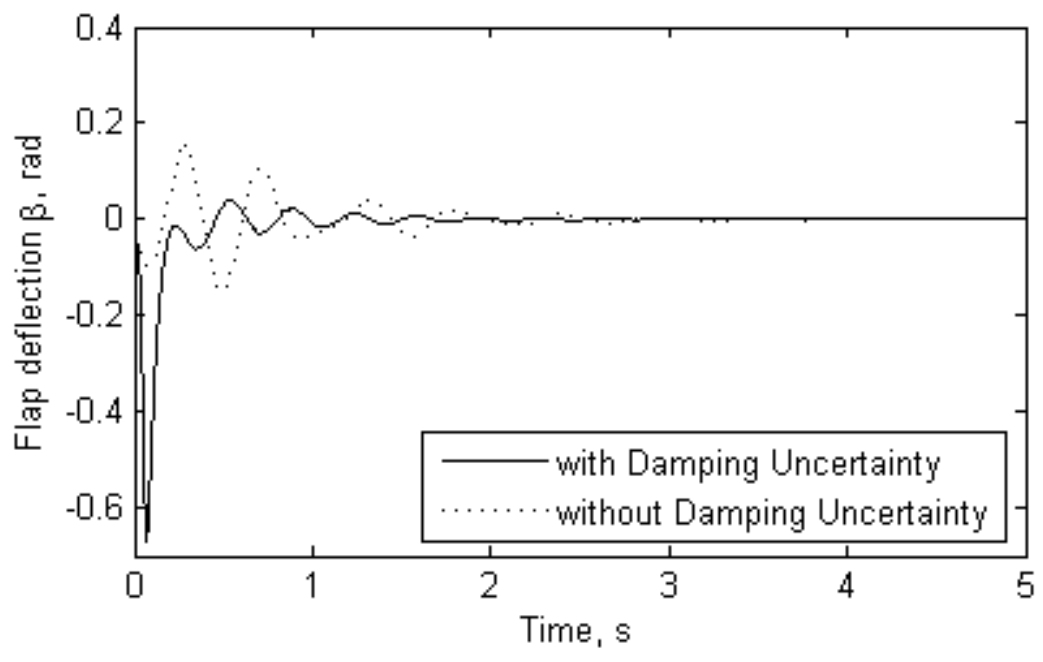

Fig. 5. Closed-loop responses with unlimited TE control deflection at $U=16 \mathrm{~m} / \mathrm{s}$, a) plunge; b) pitch; and c) flap deflection. 


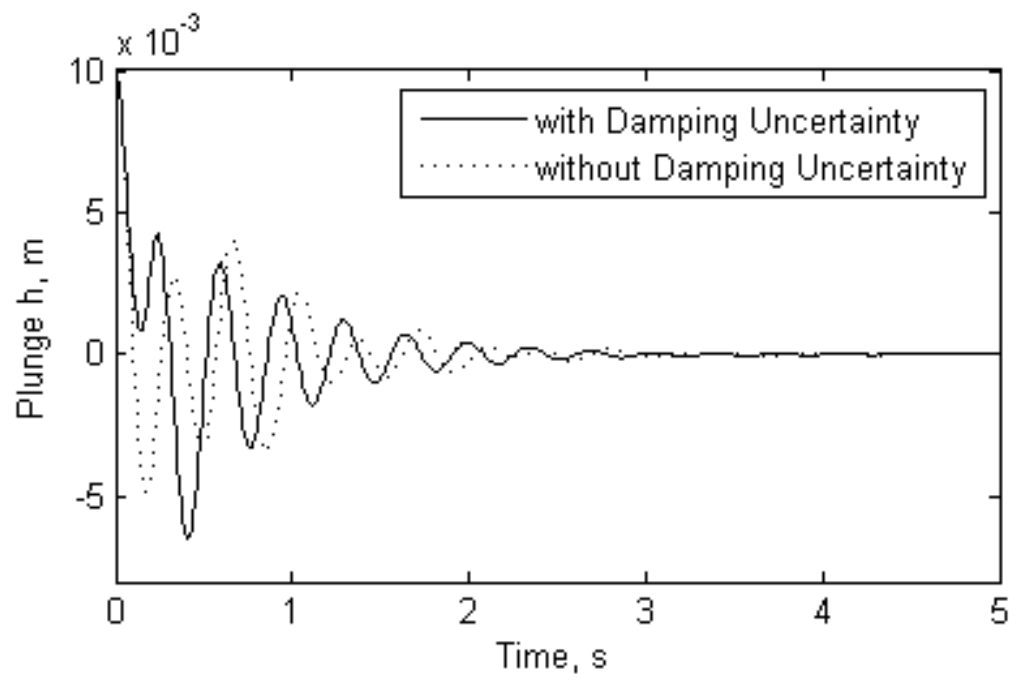

a)

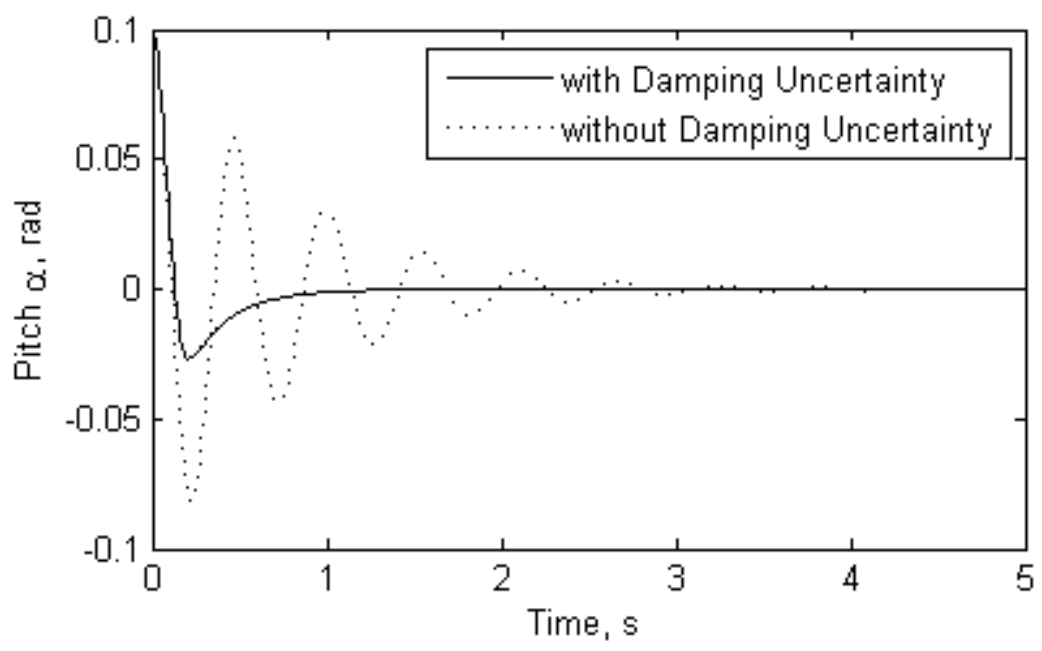

b)

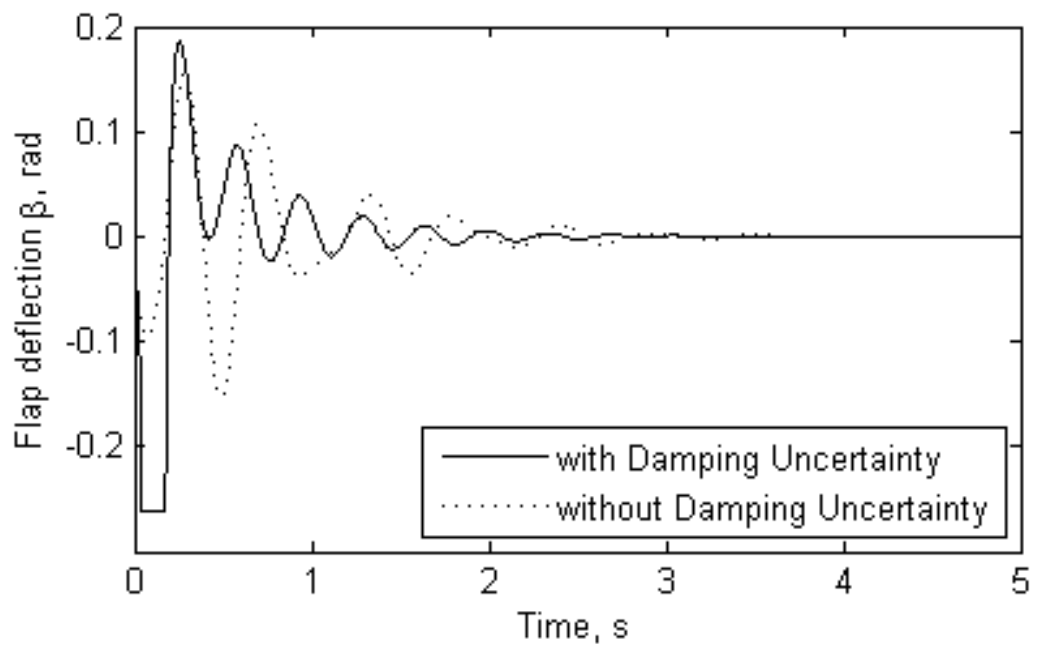

Fig. 6. Closed-loop responses with limited $T E$ control deflection at $U=16 \mathrm{~m} / \mathrm{s}$, a) plunge; b) pitch; and c) flap deflection. 

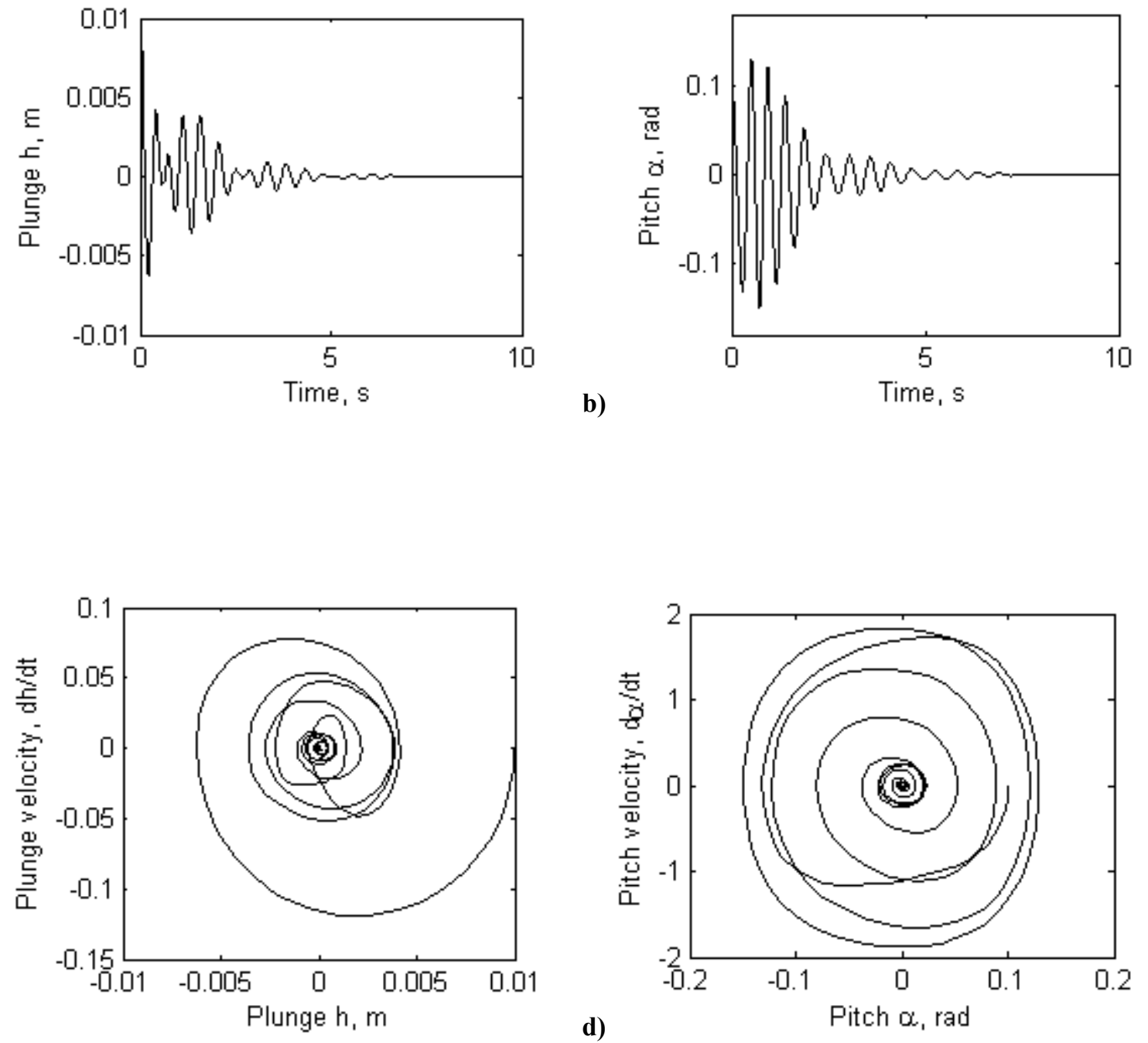

Fig. 7. Convergent time histories for $U=10.0 \mathrm{~m} / \mathrm{s}$ in a) plunge; b) pitch; and phase diagrams in c) plunge; d) pitch of open-loop system. 

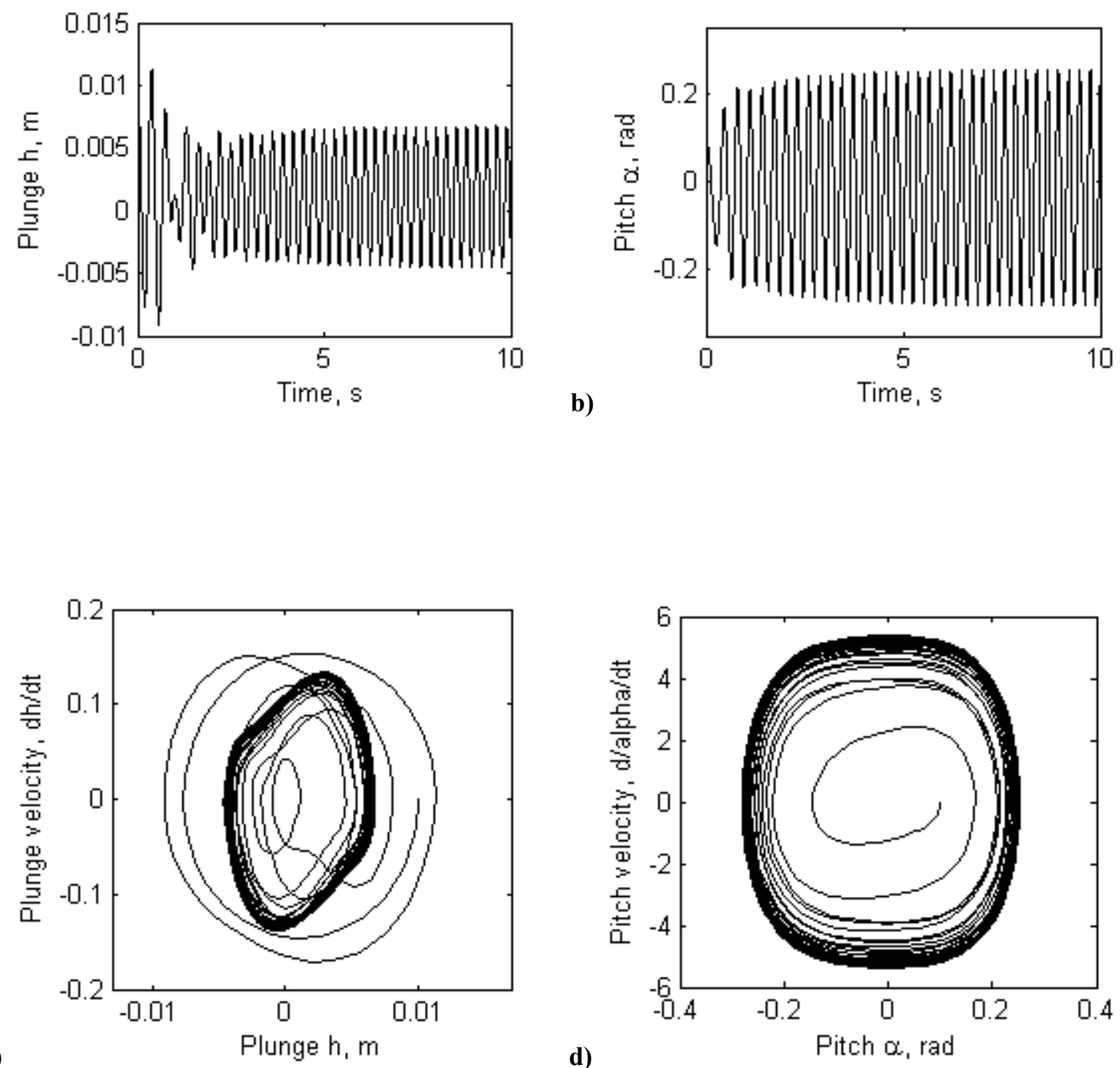

Fig. 8. LCOs time histories for $U=\mathbf{1 5 . 0} \mathrm{m} / \mathrm{s}$ in a) plunge; b) pitch, and phase diagrams in c) plunge; d) pitch of open-loop system. 


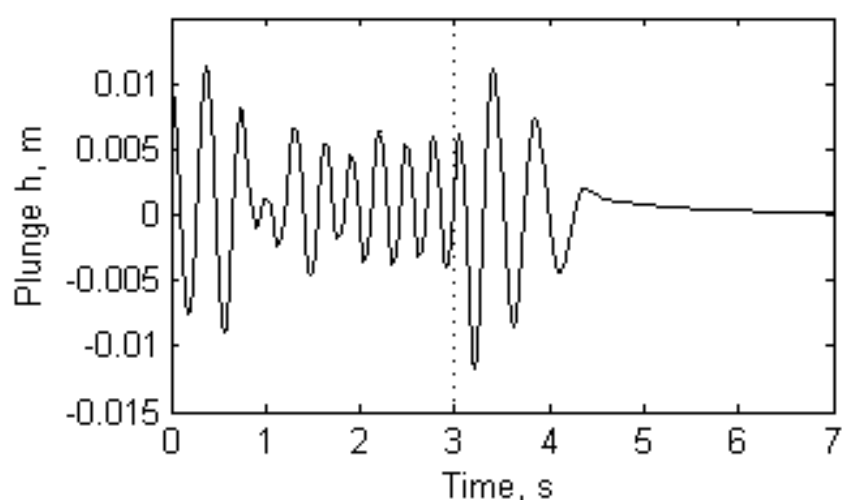

a)

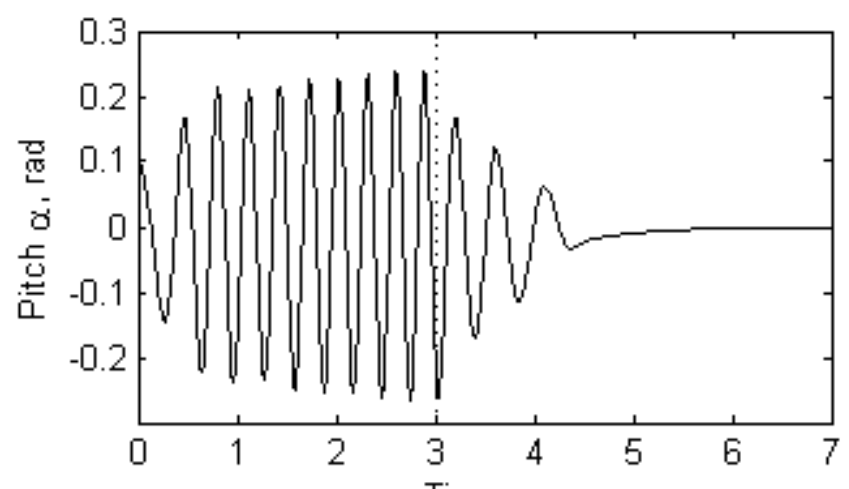

b)

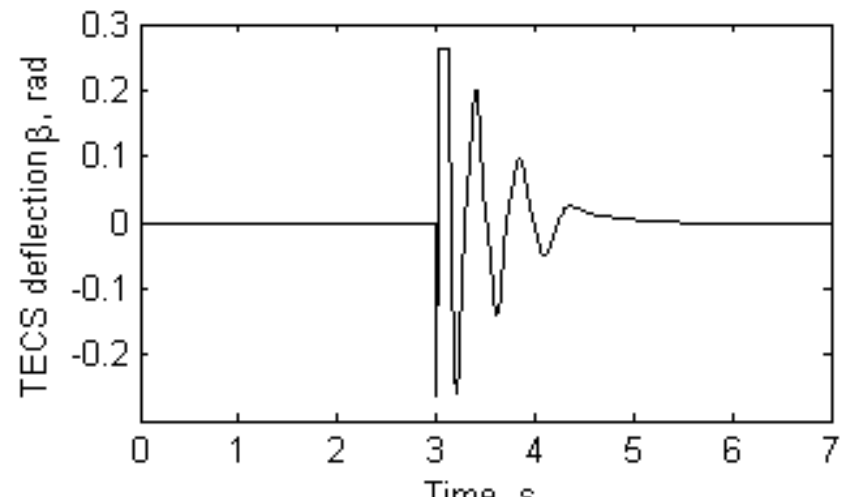

c)

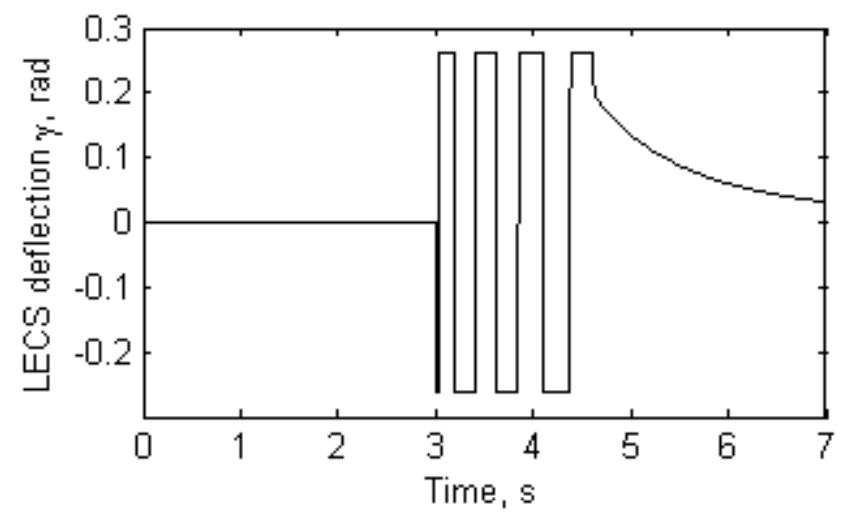

Fig. 9. Closed-loop responses with $S M R$ adaptive control law at $U=15 \mathrm{~m} / \mathrm{s}$, a) plunge; b) pitch; c) $\mathrm{TE}$ deflection; and d) LE deflection. 


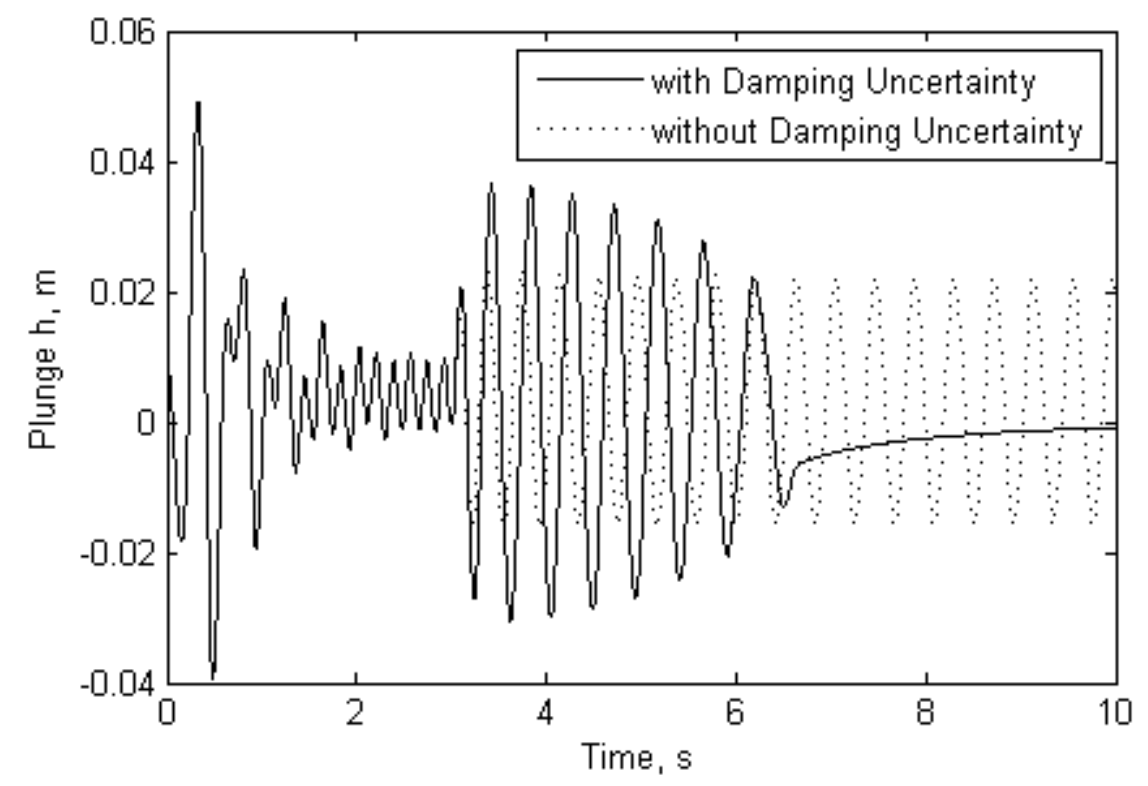

a)

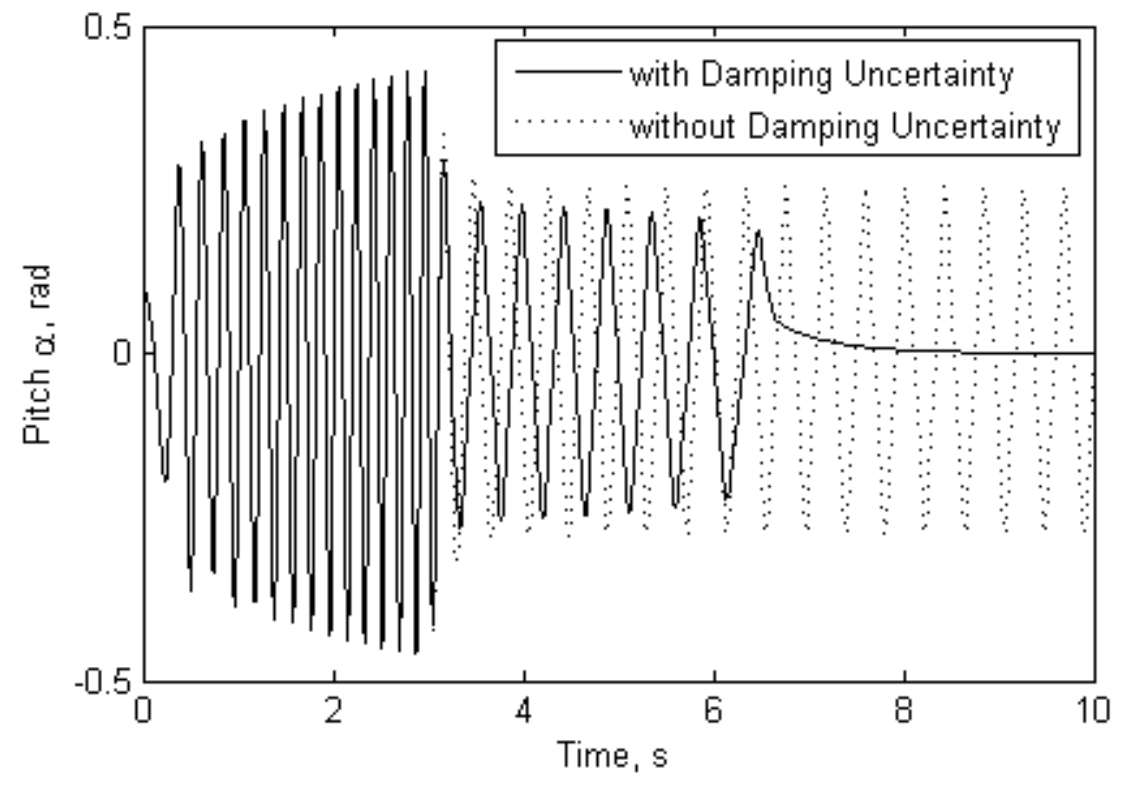

Fig. 10. Closed-loop responses with $S M R$ adaptive control law at $U=28 \mathrm{~m} / \mathrm{s}$, a) plunge and b) pitch. 


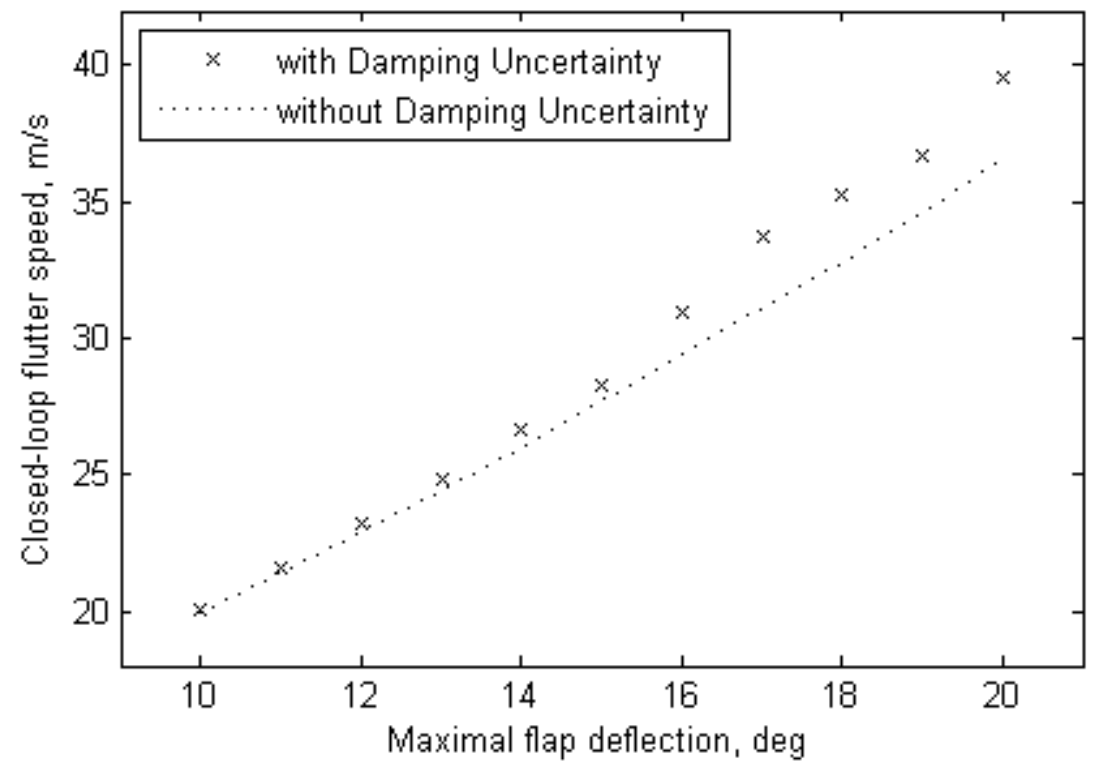

Fig. 11. Flutter speed of the closed-loop system versus control surface maximum deflection. 